\title{
An electrochemical filter to remove oxygen interference locally, rapidly and temporarily for sensing applications
}

\author{
Mathieu Etienne*, Thi Xuan Huong Le, Tauqir Nasir, Grégoire Herzog
}

Laboratoire de Chimie Physique et Microbiologie pour les Matériaux et l'Environnement, Université de Lorraine, CNRS, LCPME, F-54000 Nancy, France

* Corresponding author:

E-mail: mathieu.etienne@univ-lorraine.fr

Tel.: +33 3727473 82; Fax:+33(0)383275444

\section{Supporting Information}

\section{Table of Contents}

Table S1: Simulation parameters.

Figure S1. Concentration profiles for dissolved oxygen as a function of the potential applied after $200 \mathrm{~s}$.

Figure S2. Schematic drawing of the experimental setup.

Figure S3. Repeatability of oxygen removal.

Figure S4. Efficiency of the platinum filter.

Figure S5. Cyclic voltammetric responses to $20 \mu \mathrm{M}$ paraquat.

Figure S6. Variation of the $\mathrm{pH}$ at the sensor electrode. 
Table S1: Simulation parameters.

\begin{tabular}{|l|l|l|}
\hline Parameters & Symbol & Value \\
\hline Electrode radius & $r_{\text {cell }}$ & $2.5 \mathrm{~mm}$ \\
\hline Cell height & $h_{\text {cell }}$ & $6 \mathrm{~mm}$ \\
\hline Porous layer thickness & $h_{\text {porous layer }}$ & $125 \mu \mathrm{m}$ \\
\hline Porous layer porosity & $P$ & 0.7 \\
\hline Filter wire radius & $r_{\text {filter }}$ & 25,50, or $100 \mu \mathrm{m}$ \\
\hline Filter wire spacing & $S_{\text {filter }}$ & 100,200, or $400 \mu \mathrm{m}$ \\
\hline Wire-Electrode distance & $h_{\text {filter }}$ & $125,150,175$, or $225 \mu \mathrm{m}$ \\
\hline Dissolved O2 concentration & $C_{O 2}$ & $284 \mu \mathrm{M} \mathrm{L}^{-1}$ \\
\hline$O_{2}$ diffusion coefficient (cell) & $D_{\text {cell }}$ & $1.970 \times 10^{-5} \mathrm{~cm}^{2} \mathrm{~s}^{-1}$ \\
\hline $\mathbf{O}_{2}$ diffusion coefficient (porous layer) & $D_{\text {porous layer }}$ & $1.379 \times 10^{-5} \mathrm{~cm}^{2} \mathrm{~s}^{-1}$ \\
\hline
\end{tabular}




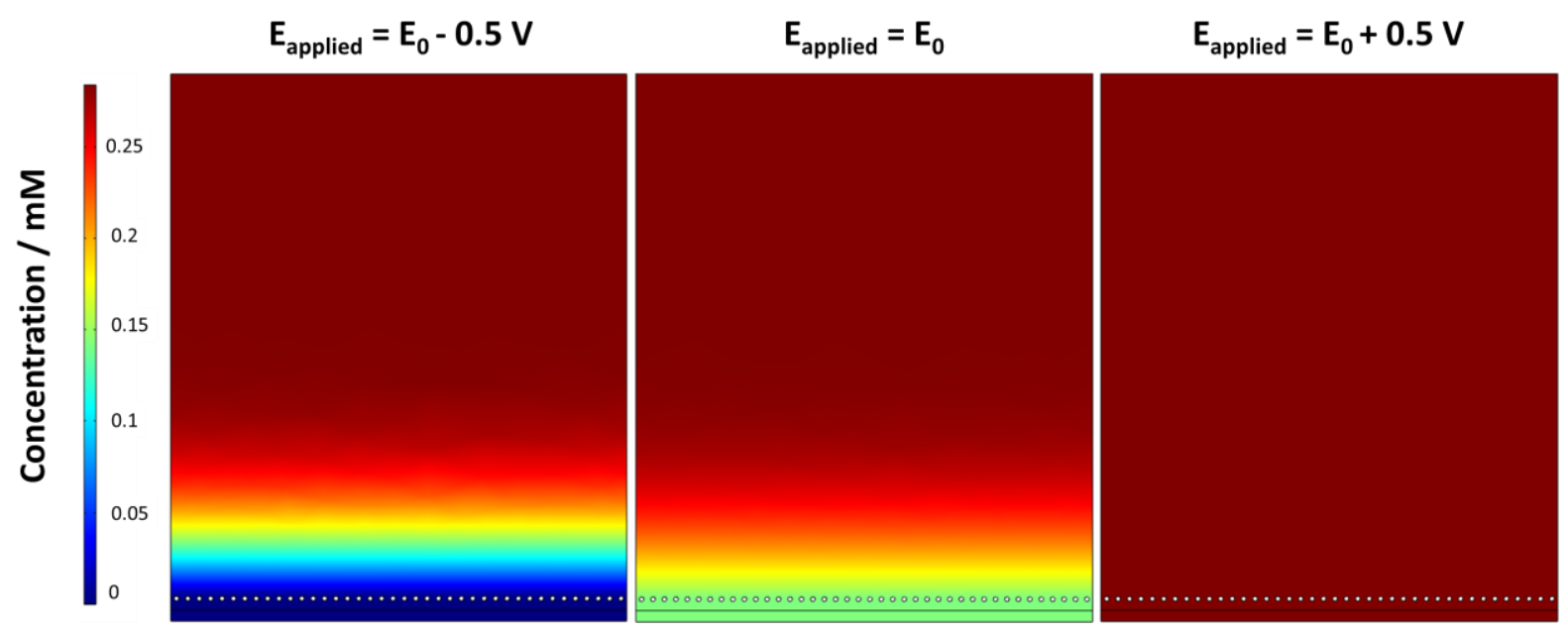

Figure S1. Concentration profiles for dissolved oxygen as a function of the potential applied after $200 \mathrm{~s}$. The geometrical parameters of electrochemical filter used were $r_{\text {wire }}=25 \mu \mathrm{m}$, $S_{\text {filter }}=100 \mu \mathrm{m}, h_{\text {filter }}=225 \mu \mathrm{m}$. Applied potentials were: $\mathrm{E}_{0}-0.5 \mathrm{~V}$ (left), E0 (middle), and $\mathrm{E}_{0}$ $+0.5 \mathrm{~V}$ (right).

In order to validate the simulation program, we ran the simulation, shown in Figure S1, at three different applied potentials for a given geometry of electrochemical filter ( $r_{w i r e}=25 \mu \mathrm{m}, S_{\text {filter }}$ $\left.=100 \mu \mathrm{m}, h_{\text {filter }}=100 \mu \mathrm{m}\right)$. These potentials values were $\mathrm{E}_{0}-0.5 \mathrm{~V}, \mathrm{E}_{0}$, and $\mathrm{E}_{0}+0.5 \mathrm{~V}$ (where E0 represents the standard redox potential of $\mathrm{O}_{2}$ ). At the oxidative potential, $\mathrm{E}_{0}+0.5 \mathrm{~V}$, the dissolved oxygen is not reduced at the electrochemical filter and the concentration at $200 \mathrm{~s}$ is the same as initially. When the potential applied is reductive, $\mathrm{E}_{0}-0.5 \mathrm{~V}$, dissolved oxygen is reduced at the electrochemical filter and the zone in the vicinity of the electrode is depleted in oxygen at $t=200 \mathrm{~s}$. When the potential applied is equal to $\mathrm{E}_{0}$, then dissolved oxygen is reduced at the electrochemical filter and the concentration of dissolved oxygen dropped in the vicinity of the electrode but full depletion is not achieved. 


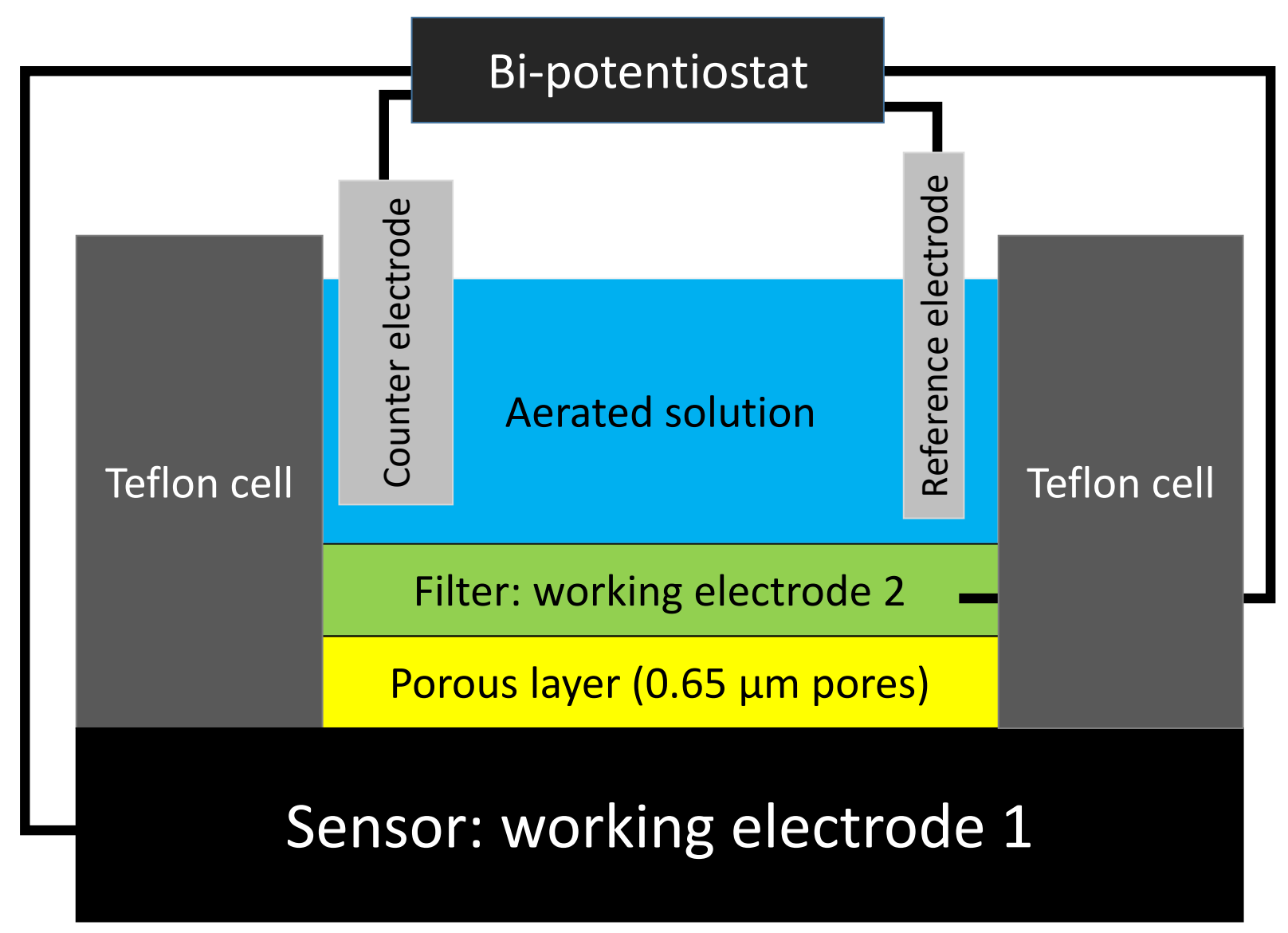

Figure S2. Schematic drawing of the experimental setup. 

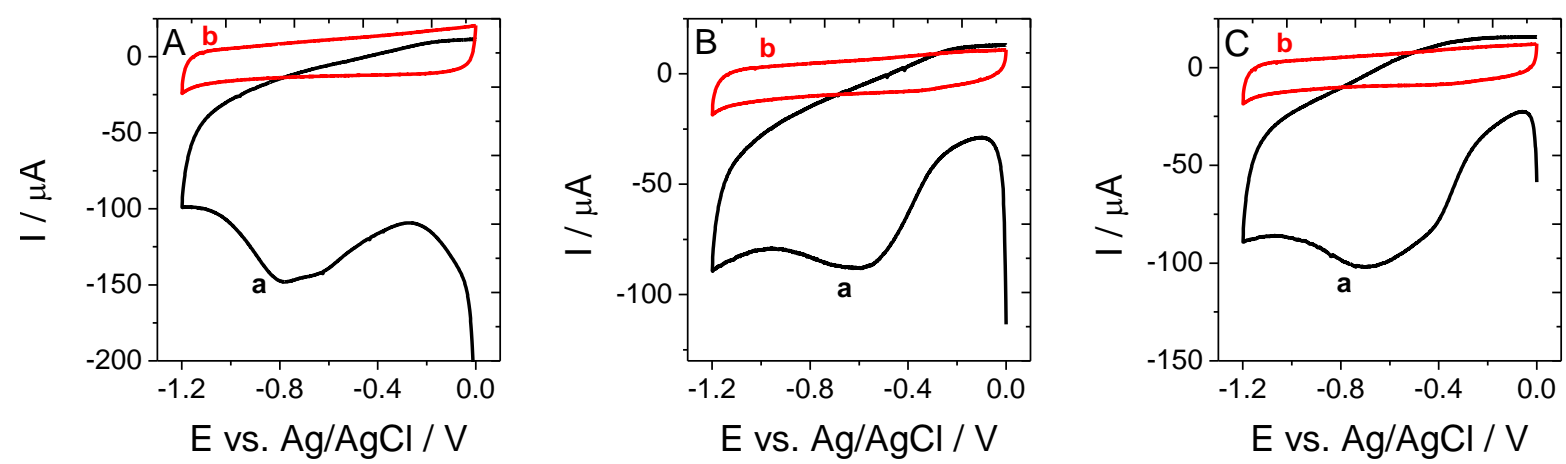

Figure S3. Repeatability of oxygen removal measured by cyclic voltammetry in aerated $0.1 \mathrm{M}$ $\mathrm{KCl}$ solution with glassy carbon electrode (a) before and (b) after activation of the oxygen filter by applying $-0.7 \mathrm{~V}$ at a stainless steel filter (scan rate: $100 \mathrm{mV} \mathrm{s}^{-1}$ ) during the (A) first cycle, (B) third cycle and (C) fifth cycle, a complete cycle comprise a measurement with filter off, a measurement after the filter was switched on for $5 \mathrm{~min}$ and the stirring of the solution. 


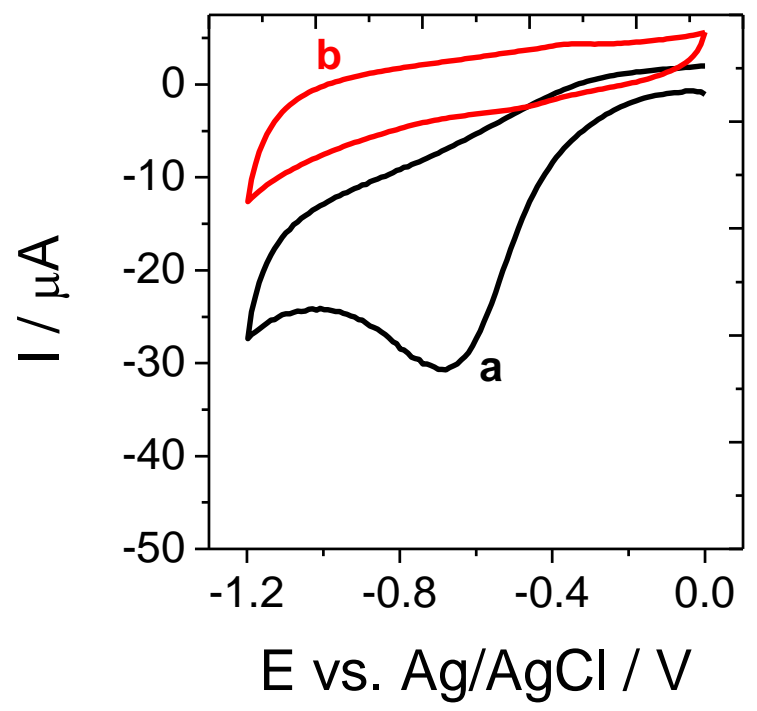

Figure S4. Efficiency of the platinum filter measured by cyclic voltammetry in aerated $0.1 \mathrm{M}$ $\mathrm{KCl}$ solution with a glassy carbon electrode (a) before and (b) after activation of the oxygen filter by applying (B) $-0.4 \mathrm{~V}$ vs. $\mathrm{Ag} / \mathrm{AgCl}$ at a platinum filter (scan rate: $10 \mathrm{mV} \mathrm{s}^{-1}$ ). 


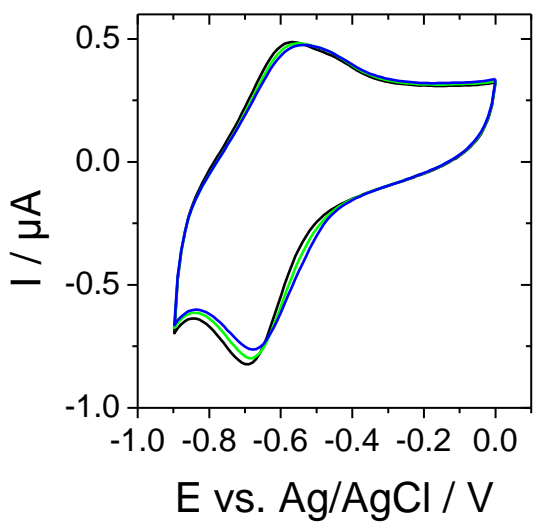

Figure S5. Cyclic voltammetric responses to $20 \mu \mathrm{M}$ paraquat in $0.07 \mathrm{M} \mathrm{NaNO}_{3}$ aerated solution at silica thin film modified GCE with local oxygen removal by applying $-0.5 \mathrm{~V}$ vs. $\mathrm{Ag} / \mathrm{AgCl}$ at a platinum filter. 


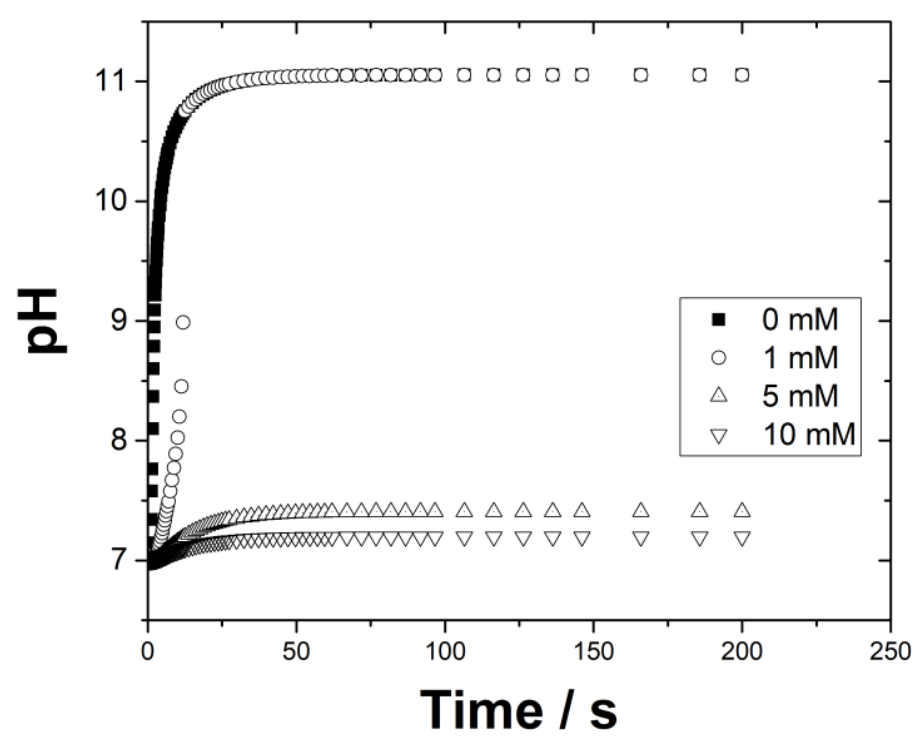

Figure S6. Variation of the $\mathrm{pH}$ at the sensor electrode in the absence (filled squares) and in the presence of 1,5 and $10 \mathrm{mM}$ (hollow symbols) of phosphate buffer ( $\mathrm{pH} 7$ ). The $\mathrm{pH}$ values are calculated based on the $\mathrm{O}_{2}$ depletion simulation results reported in Figure 2A of the manuscript, for the following electrochemical filter: $r_{\text {wire }}=25 \mu \mathrm{m}, S_{\text {filter }}=100 \mu \mathrm{m}, h_{\text {filter }}=225 \mu \mathrm{m}$.

If we consider that the $\mathrm{pH}$ of the initial solution under study is 7 , the following reaction is taking place on the filter electrode:

$$
\mathrm{O}_{2}+2 \mathrm{H}_{2} \mathrm{O}+4 e^{-} \rightarrow 4 \mathrm{OH}^{-}
$$

$\begin{array}{lll}\text { Initial conditions } & {\left[\mathrm{O}_{2}\right]_{\text {initial }}} & {\left[\mathrm{OH}^{-}\right]_{\text {initial }}} \\ \text { Time } t & {\left[\mathrm{O}_{2}\right]_{\text {remaining }}} & 4\left[\mathrm{O}_{2}\right]_{\text {reduced }}+\left[\mathrm{OH}^{-}\right]_{\text {initial }}\end{array}$

The mass conservation law is: $\left[\mathrm{O}_{2}\right]_{\text {initial }}=\left[\mathrm{O}_{2}\right]_{\text {remaining }}+\left[\mathrm{O}_{2}\right]_{\text {reduced }}$

If we assume that $D_{\mathrm{O}_{2}} \approx \mathrm{D}_{\mathrm{OH}^{-}}$, then we can calculate $\left[\mathrm{OH}^{-}\right]$at the sensor surface as a function of time, based on the simulation shown on Figure $2 \mathrm{~A}$. At the sensor surface, we can expect a rise of $\mathrm{OH}^{-}$concentration from $10^{-7} \mathrm{M}$ to $1.13 \times 10^{-3} \mathrm{M}$, which would correspond to a rise in $\mathrm{pH}$ from 7 to 11.1 (see the figure below). We then plot the $\mathrm{pH}$ values if we add to the initial solution 1,5 and $10 \mathrm{mM}$ of $\mathrm{H}_{2} \mathrm{PO}_{4}^{-} / \mathrm{HPO}_{4}^{2-}$ at $\mathrm{pH} 7(\mathrm{pKa}=7.09)$. The solution is buffered when 5 and $10 \mathrm{mM}$ of the phosphate buffer is added to the initial solution. These buffer concentrations are close to the ones generally used in various applications. 